\title{
Best practices to improve construction site safety, in the specific conditions of processing plant building
}

\author{
Blagovesta Vladkova* \\ University of Mining and Geology “St. Ivan Rilski”, 1700 Sofia, Bulgaria
}

\begin{abstract}
Construction and installation work at large industrial sites are a major challenge both in terms of meeting deadlines and ensuring healthy and safe working conditions. Force majeure circumstances that require rapid and adequate response often occur at complex sites. Construction site safety is one of the most important things during a construction project. The main reason is the accidents that occur. Presented paper's target is to shed more light on some good practices, which can lead to improved occupational health and safety. Author experienced such practices in specific conditions during processing plant construction. Such facilities are characterized by installation of special large-scale mineral processing equipment, including work in explosive atmosphere. Moreover, outdoor work in severe weather conditions is performed very often. Another very important, and at the same time difficult task, is coordinating many people, working for contractors and subcontractors. Some of the most important factors in such practice, which have a key role in the successful realization of that type of project will be discussed.
\end{abstract}

\section{Introduction}

Construction industry is a major part of an economic sector that employs a large number of people and heavy equipment. Work at construction sites is year-round and the workers are exposed to different climatic conditions. All these predicate high-risk levels which lead to occupational accidents and diseases, as shown by United Sates statistics [1].

Despite the dynamics of work in construction industry, some good practices have been proven in practice - technical and organizational solutions, compliance wherewith leads to a significant reduction of incidents. This, of course, is an interaction of many factors. First is the role of company management in understanding the importance of safe working conditions on site. Next comes experienced Occupational Safety and Health (OSH) experts and proper implementation in practice of safety regulations. When talking about a large construction site, it is clear that main contractors, as well as subcontractors, different companies are involved. It is of utmost importance to lay down clear working rules, still at contract level, to be strictly observed during construction and assembly work. Why is safety

\footnotetext{
Corresponding author: b vladkova@yahoo.com
} 
so important? On the one hand, when accidents occur, injured personnel are away from work and might have sustained temporary or permanent disability, while on the other hand, company is exposed to financial and material losses [2].

This paper is based on the actual experience of the author as HSE-expert in construction and installation works of processing plants. General arrangement plan of the site is presented on Fug. 1. The said experience is translated into a safety procedure described here below including individual key components that are essential for its implementation. Such procedure may have its practical application in the work of HS experts and in the training of employees. Because of confidentiality requirements, specific data for the site cannot be provided.

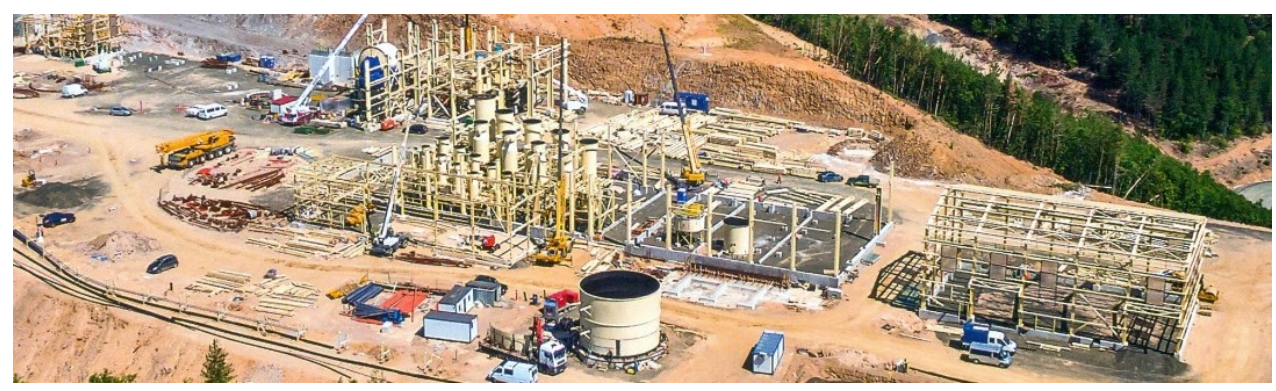

Fig. 1. Processing plant construction site

\section{Types of Construction Accidents}

Some common types of construction accidents include:

- Crane or hoist accidents. Cranes and hoists are important construction tools. However, lack of training, operator errors, and other factors can lead to serious accidents on construction sites.

- Falls from heights. Scaffolding accidents, ladder accidents, roofing accidents, and other falls from heights can be lethal.

- Slip and falls. A slip and fall on the ground can cause broken bones, sprains, and other injuries.

- Repetitive stress injuries. Repetitive nature of some construction work can result in repetitive stress injuries in the back, wrists, ankles, and joints.

- Gas leaks, fires, and explosions. Gas leaks, fires, and explosions can be sudden and deadly. Carbon monoxide, for example, can be dangerous in a confined construction space.

- Forklift accidents. Without proper training and alert operators, forklifts can be dangerous and may result in serious construction accidents.

- Trench accidents. A trench collapse or an accident within a trench can be devastating. A construction worker may be trapped and unable to get out on their own.

- Elevator shaft accidents. Construction workers may be at risk of falling down elevator shafts if safety precautions are not observed.

- Electrocutions. Electrical equipment, overhead electrical wires, wiring, and lightning all create risks of electrocution for construction workers.

- Machinery accidents. Heavy machines perform great deal of construction operations, but these also create risk situations for construction workers either because of malfunction of machinery or operator's fault. 
- Struck-by accidents. Motor vehicles are common on construction sites. Construction worker is at risk of being hit by a motor vehicle or part of machinery while working on a construction site.

- Caught-between accidents. A limb of a person or entire body may get caught by a piece of equipment or crushed by the debris of a construction incident.

- Exposure to hazardous or toxic chemicals. Inhalation of chemicals or toxic vapors by construction workers can cause severe respiratory problems. [3].

Occupational Safety and Health Administration (OSHA) has reported that one of ten construction site workers are injured every year. OSHA also reports that fall hazards are the leading cause of injury at construction sites. There are roughly 150,000 construction site accident injuries yearly according to the Bureau of Labor Statistics (BLS).

The BLS also reports that while falls make up the majority of the construction site accidents, contact with equipment is also a significant cause of injury for workers.

Workers between 25 and 34 years old are most likely to be injured in a construction site accident. Most construction site injuries involve workers' backs, spines and trunks. National Institute for Occupational Safety and Health (NIOSH) reported that yearly 1,224 construction workers died at the workplace, which makes the construction industry the most hazardous industry in the country. Construction workers' compensations amount to as much as 15 percent of all expenses of insurance companies, covering injuries in all industries. [4].

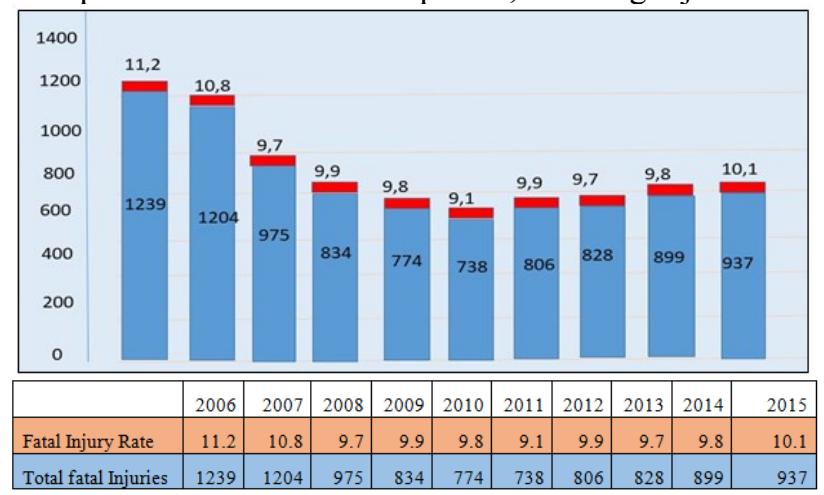

Fig. 2. Construction Worker Fatalities\& Fatal Injury Rates, Data for USA [17]

According to reports of the National Social Security Institute, Bulgaria [9], the number of labor accidents in the construction sector remains relatively the same in recent years, these representing an average $8 \%$ of the total number of labor accidents in the country (Fig.3).

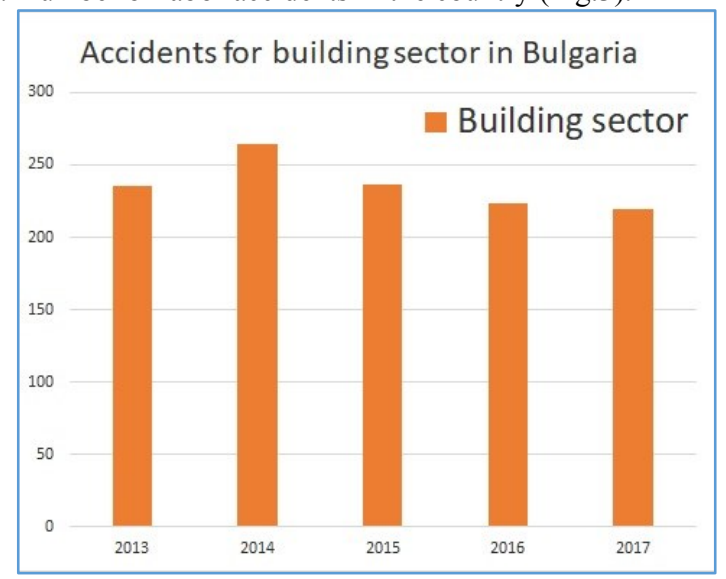

Fig. 3. Accidents for building sector in Bulgaria (2013-2017), [9] 


\section{Safety procedure in the specific conditions of processing plant construction}

The sequence of operations presented here below is recommended for successful application of the procedure. Links between individual modules are presented on Fig. 4.

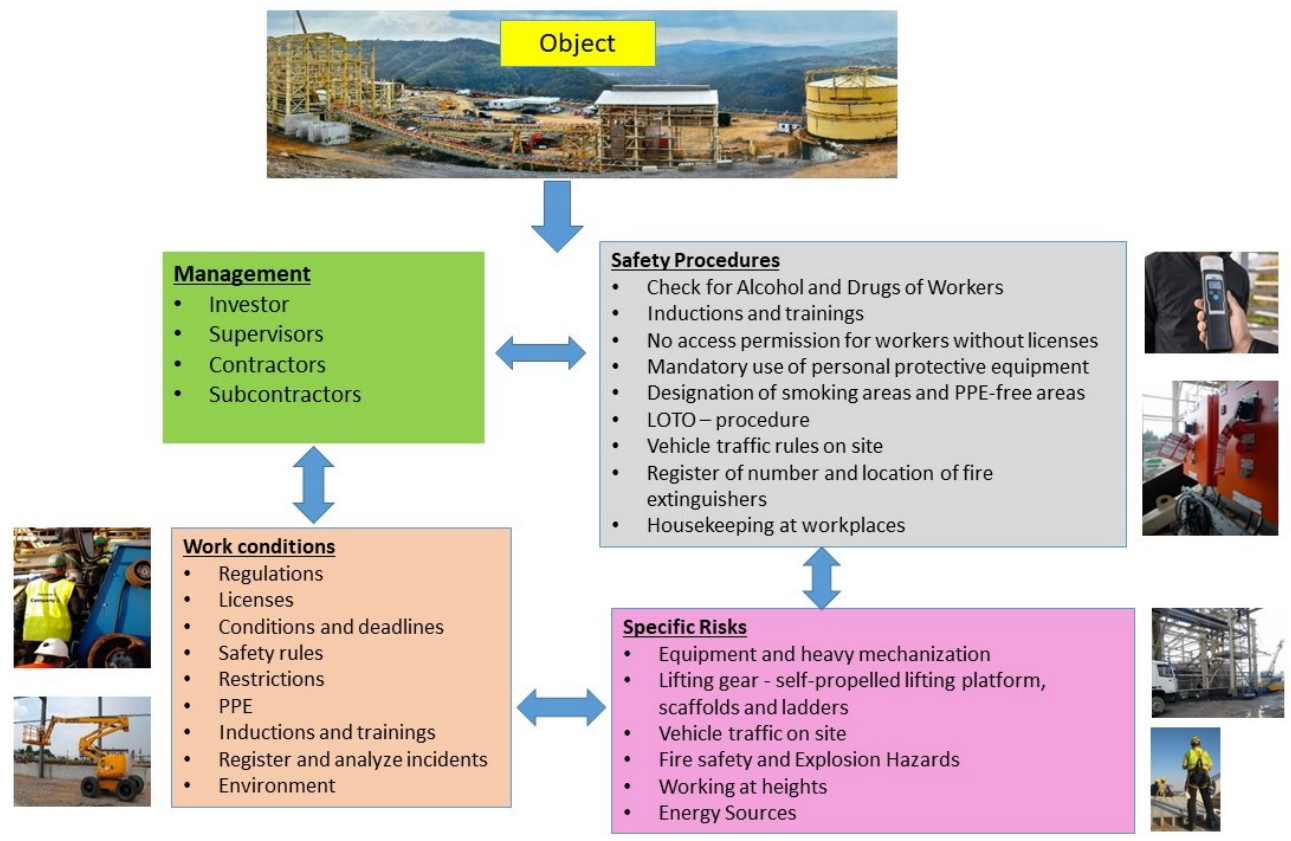

Fig. 4. Safety procedure

- Regulations and Contract between Contracting Authority and Site Contractor

It is very important for the conditions of work and safety to be set at the beginning, when signing a contract between the contracting authority and the contractors/subcontractors. This is the stage where the specific requirements, sanctions, rules of work are specified. At that stage, provisions of national law and applicable standards should be included $[10,11,12,13,14]$.

\section{- Instructions and trainings}

Instructions are required before allowing workers to the construction site. Adequate information on types of potential site hazards should be provided. It is important for the initial instructions to be documented and instructed workers to do a test. Tests and records in induction books are important for documenting the results and creating an archive.

- No access permission for workers without licenses

Every construction site has people with different qualifications - electricians, welders, crane operators, operators of road construction machinery and heavy equipment. Occasionally, unqualified workers are allowed to perform a task, which increases the risk of accidents. Therefore, strict control of licenses for each activity, copies of license documents and archive storage should be ensured.

- Mandatory use of personal protective equipment (PPE) at the workplace 
One of the main problems in Bulgaria is the general safety attitude at the construction site. Workers often underestimate the importance of PPE, do not wear them all the time, causing incidents and accidents. Typical mandatory PPEs include helmets, boots, goggles and signal workwear. Practice shows that financial sanctions are most effective. When a large number of companies work on a construction site (for example more than 400 workers), it is very important for people to be easily recognizable. This can be achieved by having the printed logo or the company name on working clothes. In this way the control over the activity / resp. the sanctions against each company and employee are very easily applicable.

\section{- Check for Alcohol and Drugs of Workers}

Practice in Bulgaria shows that often people working at construction sites use alcohol at work. The best way to solve this problem is to introduce a control test for alcohol content before admission to work and the appropriate sanctions for people who violate this rule. Very good results are reported and more and more companies are starting to implement such measures. Similarly, this applies to the use of narcotic drugs.

\section{- Designation of smoking areas and PPE-free areas}

When stringent working rules are set at the site, rest areas where smoking is permitted and where not wearing PPE is allowed should be regulated. This contributes to the good organization and order of the site.

\section{- Equipment and heavy mechanization reliability}

Construction of processing plant should take into account specifics of special mining equipment as well as amassing of large number of machines and heavy mechanization necessary for construction and installation works.

Access onto the site and use of machines (motor vehicles, cranes, other lifting equipment), is only allowed after careful check of documents (technical inspection and revision books). It is obligatory for the operator to submit a qualification document. In general, the overall performance and maintenance of mining machinery and equipment is of great importance.

\section{- Vehicle traffic rules on site}

First and very important rule is speed limit. The speed must not exceed $30 \mathrm{~km} / \mathrm{h}$, and sometimes there are areas with even lower limits $-10 \mathrm{~km} / \mathrm{h}, 20 \mathrm{~km} / \mathrm{h}$. Phone calls during driving are prohibited, unless with hands-free. Another important rule on site is to park the vehicle so that it is ready for immediate departure without additional maneuvers. It is obligatory for the vehicle to have an additional light signaling (beacon) and a properly functioning fire extinguisher.

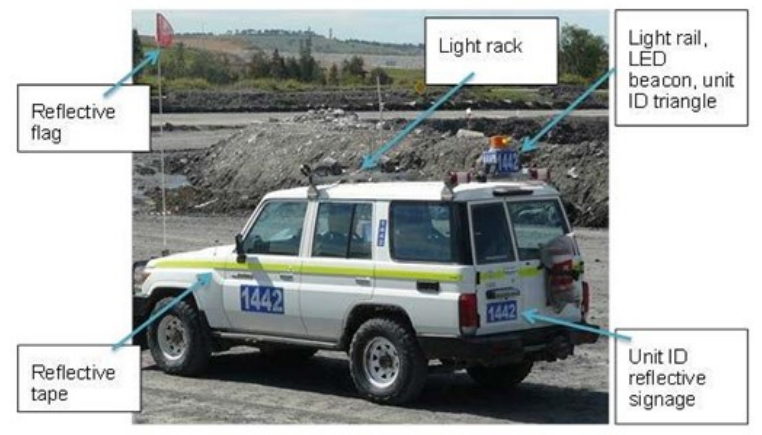

Fig. 5. Equipment and signaling of the vehicle on site [6]

\section{- $\quad$ Fire Safety and Explosion Hazards}

Each site should have fire safety plan. Depending on site type and performed activities, type of fire extinguishers (with chemical powder, water, $\mathrm{CO}_{2}$ and special) is selected. A register of the number and location of fire extinguishers should be established, 
accompanied by annual technical inspection and marked locations. Sometimes certain facilities are at increased risk of explosions. For the processing plants these are the reagent compartments and the storage compartments of pressurized gas cylinders. For areas with explosive atmospheres, proper ventilation and additional supply of inert gas are important. A good practical solution is wind ventilation [5] - no electrical supply and special coating for work in harsh atmospheres.

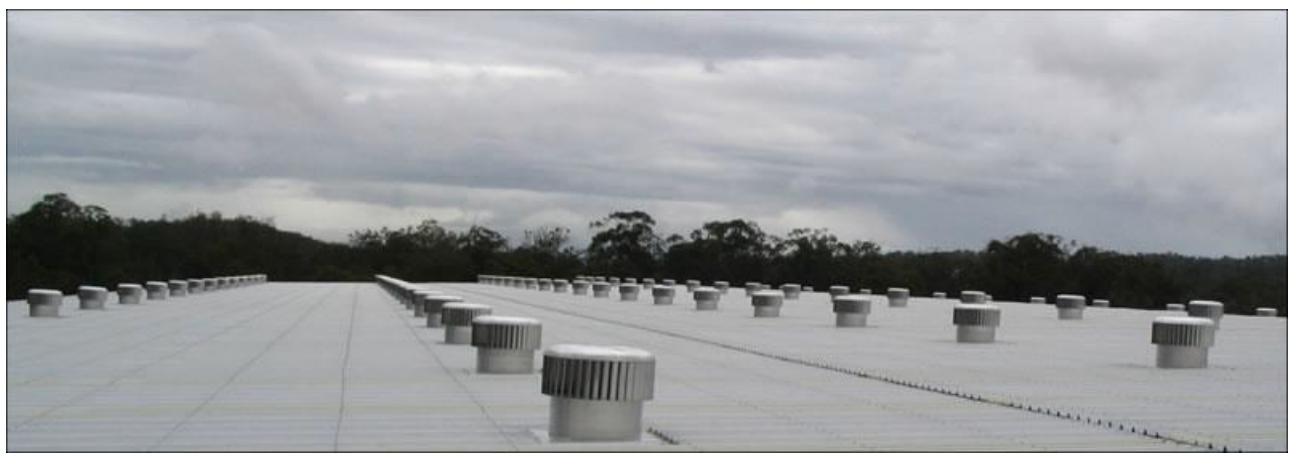

Fig. 6. Example of wind ventilation application, (Dinchev Z, 2016) [5]

\section{- Working at heights}

Work at heights entails many hazards of various nature for the workers. The reasons for that is the use of different types of machines and equipment as the fact that the height factor is added to the common hazards associated with installation works. Metal structures usually require welding and use of lifting devices. When working at heights, there are two important elements: specific personal protective equipment available to protect the worker against falls and lifting gear - self-propelled lifting platform, scaffolds and ladders. When working at height a harness is mandatory. Before work, harness should be thoroughly checked. Technology development in lifting devices allows application of modern facilities such as self-propelled lifting platforms, scaffolds, ladders. Each of these has strict requirements and applications. The main role of OSH experts is to ensure permanently that malfunctions of PPE and equipment is not possible and not allowed on work site. Sometimes workers underestimate dangerous situations or their long experience makes them over confident. Practice shows that even the most innocent at first glance situation can lead to a serious accident.

\section{- $\quad$ Lock Out Tag Out (LOTO - procedure)}

The essence of this procedure is securing areas with different energy sources (electricity, steam, pressure, vapor, mechanical energy). Always isolate the source before work so that there is no accidental start of the power supply and increased risk of accidents. Using personal padlocks and keeping a padlock register is important for administering the process. This procedure is not often implemented in Bulgaria, the role of HSE-experts is to establish it as a common practice. For the plant presented herein, it was part of a safety procedure and was well accepted by workers.

- Good housekeeping at workplaces

Housekeeping at workplace is very important for safety at construction site. This can reduce accidents and contribute to raising the overall level of safety culture. For the proper realization of this goal, it is good to regulate daily cleaning and tiding of workplaces and provide containers for waste collection.

\section{- $\quad$ Register and analyze incidents}


When there are incidents and accidents, it is important to investigate the causes, analyze the facts and learn lessons from them. This would be a prerequisite for choosing preventive actions and preventing such cases in the future. Good practice from Canadian companies is sharing experience: when an accident occurs in a company, colleagues are notified about what has happened to prevent similar situations in the future and in other companies. Unfortunately, in Bulgaria the practice is in the opposite direction - when an incident occurs, the aim is not to give publicity. This is an area where work can be done to improve corporate culture.

\section{- Environment and sustainable development}

When it comes to activities on a large mining site - an opencast mine and a processing plant - it is clear that protection of the environment is of utmost importance. This topic includes mining waste management, waste process water management [7], reagent handling, mining operations, dust emissions, and more.

\section{Conclusion}

The safety of construction works in the mining industry is extremely important and there are a number of factors in its implementation. Practice shows that a high level of safety can be achieved with an experienced team of 4-7 people for a company of 200-500 workers on the site. Financial resources should be available for this task. Sometimes large companies underestimate the role of OSH unit, and with few people and without enough money, the results are far below expectations. There are many examples of good practice worldwide, exchange of experience and training would also be beneficial. The author's experience presented in this paper shows that implementation of the components of the procedure described herein has yielded very good results in terms of work safety and has motivated project participants.

\section{References}

1. Arya Hojati: 8 Best Practices to Improve Construction Site Safety, https://esub.com/improveconstruction-site-safety/, December, 2018

2. Edgar Snyder \& Association: Construction Site Accidents, https://www.edgarsnyder.com/jobsite-accident/construction-site-accidents/

3. Steve Lee, http://www.attorneystevelee.com/library/types-of-construction-site-accidents.cfm

4. James R. Keller: Construction Accident Statistics: https://www.2keller.com/library/constructionaccident-statistics.cfm

5. Dinchev Z, "Wind ventilation of industrial explosives storage facilities", Annual of the University of Mining and Geology "St. Ivan Rilski", Volume 59, part II, Mining and Mineral Processing, Sofia, 2016, p.64-71, (ISSN 1312-1820);

6. Ravensworth Vehicle Collision 2013, http://mineaccidents.com.au/mine-event/216/ravensworthvehicle-collision-2013

7. Kisyova T, Radulov G.: "Automation of waste water treatment by mining companies", $\mathrm{X}$ Mineral Processing Congress, 15-20 June 2003, Varna, Bulgaria, pp 543-547

8. Iliev Zh., Perenovski N.: "Computer modeling and investigation of the operating parts of the screw conveyor by finite element method ", Fifth National Scientific and Technical Conference with International Participation,2016, Devin, Bulgaria pp.54-62

9. Bulgarian National Social Security Institute, http://www.noi.bg/aboutbg/st/statistic/304tzpb/infotz

10. ISO 45001 - Occupational health and safety management systems - policies and OHS plans

11. Bulgarian Regulation 2, March 2004, For the minimum requirements for healthy and safe working conditions during construction and assembly work, Ministry of Labour and Social Policy of the Republic of Bulgaria (BG text) 
12. BG Regulation on safety operation and technical supervision of lifting equipment, Gov. Decree 199/ 10.09.2010, promulgated SG \# 73/17.09.2010 (BG text).

13. BG Regulation $7 / 23.09 .1999$ on minimum requirements for safe and healthy working conditions at workplaces and during operation of equipment. Issued by the Minister for Labor \& Social Policy and the Minister for Health, promulgated SG \# 88/ 8.10.1999, in force since 9.01.2000, as amended SG\# 48/ 13.06.2000, in force since 1.01.2003, as amended SG\# 95/ 29.11.2016, in force since 1.03.2017.(BG text)

14. ORDINANCE ON ESSENTIAL REQUIREMENTS AND COMPLIANCE ASSESSMENT OF PRESSURIZED EQUIPMENT, in force since 19.07.2016, adopted by virtue of Gov. Decree 91/ 21.04.2016, promulgated SG \# 33/ 26 April 2016 (BG text).

15. http://www.avv-bg.com/building-mechanization/, Self-propelled lifting platform

16. http://www.pik3000.com/categories/list/name/predpazni_kolani.html, Harness for working at height

17. https://www.constructconnect.com/blog/construction-news/construction-leads-industries-workerdeaths/ 